\title{
Moderate to severe psoriasis treatment challenges through the era of biological drugs*
}

Júlia Vide ${ }^{1}$

Sofia Magina ${ }^{1,2}$

DOI: http://dx.doi.org/10.1590/abd1806-4841.20175603

\begin{abstract}
Biological therapy has revolutionized moderate to severe psoriasis treatment. However, despite being more effective than conventional systemic treatments, some patients do not respond or lose response to biotechnological treatments or develop drug-antibodies, interfering with its safety and efficacy. There are also clinical forms of the disease and patient profiles for which is pending further scientific evidence for more sustained therapeutic interventions. The continuous and more detailed knowledge of psoriasis pathophysiology has allowed identifying new therapeutic targets, which is expected to help overcome the challenges of individualized psoriasis treatment.
\end{abstract}

Keywords: Biological factors; Biological therapy; Biological treatment; Clinical trials as topic; Psoriasis; Therapies, investigational

\section{INTRODUCTION}

Psoriasis is a chronic inflammatory dermatitis, immunologically mediated, with a prevalence estimated in $2-3 \%$ of the Caucasian population. ${ }^{1,2}$ It is estimated that $17 \%$ of patients have moderate to severe psoriasis, requiring systemic treatment. ${ }^{3-4}$

Psoriasis has a strong psychosocial impact, interfering with patients' quality of life. ${ }^{2}$ In addition, it is frequently associated with comorbidities such as psoriatic arthritis, cardiovascular disease, obesity, non-alcoholic fatty liver disease, metabolic syndrome and inflammatory bowel disease, which may interfere in the quality of life of these patients and reduce their mean life expectancy. ${ }^{5-7}$

Progressive knowledge on immunopathogenic pathways of psoriasis allowed the development of drugs aiming at specific molecular targets. Anti-TNF (adalimumab, etanercept and infliximab), anti-IL-12/IL-23 (ustekinumab) and 17A (secukinumab) biological drugs are currently approved and available in Portugal for the treatment of plaque psoriasis. Although these agents have revolutionized psoriasis treatment, medical needs remain to be satisfied for the control of this disease and its associated comorbidities. ${ }^{8}$

\section{NEW THERAPEUTIC TARGETS}

Before 1980, psoriasis was understood as a disease primarily of the keratinocyte. Over the next 20 years, the role of the immune system has been recognized and is currently considered an immune-mediated disease involving the activation of innate and adaptive immunity. ${ }^{9-10}$
The growing knowledge on molecular and cellular bases involved in the pathogenesis of psoriasis has allowed the development of biological therapies directed to $\mathrm{T}$ lymphocytes and cytokines TNF $\alpha$, IL-12, IL-23 and IL-17A. ${ }^{9-10}$

Selective IL-23 inhibitors are being developed, such as tildrakizumab and guselkumab, which have been showing to be safe in the defense against intracellular microorganisms over IL-12/ IL23 inhibitor by maintenance of IL-12/Th1/IFN $\gamma$ axis, already approved. ${ }^{11-12}$

Recently, the role of Th17 cells has been recognized in the proximal regulation of psoriatic cutaneous inflammation. ${ }^{9-10}$ IL-17A, the main effector cytokine produced by Th17 cells, stimulates keratinocytes to produce inflammatory mediators, establishing itself as a cytokine for binding between the innate and acquired pathways of the immune system. The present pathophysiological model of psoriasis establishes the potential for therapeutic intervention through the inhibition of the IL-17 pathway, with several monoclonal antibodies directed to this pathway, such as the recently approved secukinumab and the ones in development, ixekizumab and brodalumab, which represent a new therapeutic approach for moderate to severe psoriasis. ${ }^{13-14}$

Tregalizumab, another biotechnological agent under study in the treatment of psoriasis, which acts through the specific stimulation of a CD4 epitope, has the potential to exclusively activate regulatory $\mathrm{T}$ lymphocytes without activation of effector T lymphocytes,

Received on 20.01.2016.

Approved by the Advisory Board and accepted for publication on 03.07.2016.

* Study conducted at Centro Hospitalar de São João - Porto, Portugal.

Financial support: none.

Conflict of interest: none.

Dermatology and Venereology Service, São João Hospital Center, EPE - Porto, Portugal.

Department of Pharmacology, School of Medicine, University of Porto - Porto, Portugal.

C2017 by Anais Brasileiros de Dermatologia 
with an increase in anti-inflammatory cytokines (IL-10 and TGF- $\beta$ ), thus contributing to the disruption of the inflammatory cascade. ${ }^{15}$

An antagonist of toll-like receptors (TLR) 7, 8 and 9 is also under investigation for its potential in reducing the expression of proinflammatory cytokines dependent on IL-23/Th17 axis. ${ }^{16}$

The possibility of acting on intracellular targets has also been the object of study. Inhibition of the JAK/STAT pathway has been appealing, since JAK proteins family play a central role in signal transduction between the lymphocyte cytokine receptor and STAT proteins, involved in the immune responses promoted by lymphocytes. ${ }^{17}$ Tofacitinib, a JAK1 and JAK3 inhibitor administered orally or topically, and ruxolitinib, a JAK1 and JAK2 topical inhibitor, are the best studied JAK/STAT inhibitors to date. ${ }^{17-19}$ Inhibition of the cAMP/PKA pathway is also being investigated for the treatment of psoriasis. Inhibitors of phosphodiesterase 4 increase the intracellular levels of cyclic adenosine monophosphate (cAMP), thus inhibiting the production of pro-inflammatory mediators. Apremilast, a small inhibitory molecule specific for phosphodiesterase 4 , is representative of this new therapeutic class and has recently been approved for the treatment of psoriatic arthritis. ${ }^{20-21}$

To date, in the treatment of psoriasis, there are 970 clinical trials registered at ClinicalTrial.gov, 170 of them are open.

\section{PSORIASIS TREATMENT}

Traditional systemic therapies (methotrexate, cyclosporine and acitretin) and phototherapy (UVB 311nm and PUVA) are the first line of treatment in moderate to severe psoriasis. ${ }^{22}$ However, they present some limitations that condition their use over long periods of time, such as cumulative toxicity of target organs and potential drug interactions. ${ }^{23-25}$ In a study in Sweden, at the end of one year of conventional systemic therapy, $47.9 \%$ of patients did not maintain their respective treatment. ${ }^{26}$ In another study investigating the limitations of systemic therapies and UVB phototherapy in patients with moderate to severe psoriasis using a questionnaire applied to patients $(n=301)$, contraindications to traditional treatments were found in $9 \%$ to $22 \%$ of patients. ${ }^{24}$

Appearance of biotechnological therapies has revolutionized the treatment of psoriasis, but patients who do not respond to these drugs (primary inefficacy) continue to exist, as well as patients who respond initially but lose the response with continuity of treatment (secondary inefficacy), patients who respond, but don't reach the desired magnitude of response (partial response) and patients who have to discontinue treatment due to safety reasons (intolerance or toxicity), these being the four reasons for inadequate response to a biolog- ical agent. ${ }^{27}$ Retention rates or persistence rates in a given biological agent are thus very useful in assessing the "added value" of therapy in daily clinical practice, since, on the one hand, they reflect the proportion of patients with adequate response and, on the other, provide data on effectiveness, since in clinical practice the effectiveness may be different from that obtained in clinical trials..$^{28-29}$

The efficacy of biotechnological drugs in the treatment of moderate to severe psoriasis, approved in the European Union by 2014, was subject of a systematic review and meta-analysis of randomized and controlled clinical trials versus placebo of adalimum$\mathrm{ab}$, etanercept, infliximab and ustekinumab (Table 1). ${ }^{30}$

Secondary inefficacy, relative to PASI75 response, was quantified at $20 \%$ to $32 \%$, from 0.8 to 3.9 years of follow-up, in a review of the longer phase III trials with adalimumab, etanercept, infliximab, and ustekinumab. ${ }^{31}$

In a significant proportion of patients, therapy was changed in the first year of treatment. Rates of persistence with biotechnology therapy in daily clinical practice at the end of one year ranged from $22 \%$ to $85 \%$ in different studies. ${ }^{32-34}$ In the Italian observational study OSCAR, at 29 months of treatment, $81 \%$ of patients maintained their treatment with etanercept, 59\% with adalimumab and $62 \%$ with infliximab. ${ }^{35}$ However, in the Danish registry DERMBIO, the highest median retention rate was obtained with ustekinumab, followed by adalimumab and infliximab (59 months) and, finally, by etanercept (30 months). ${ }^{36}$

The most frequent reason for discontinuation was the therapeutic ineffectiveness. ${ }^{35-38}$ In DERMBIO, the ineffectiveness caused $67 \%$ to $75 \%$ of the discontinuations, with the occurrence of adverse events being the second cause of discontinuation, in $9.7 \%$ to $12 \%$ of the cases. ${ }^{36-37}$ In the Italian multicenter observational study, discontinuation treatment due to primary inefficacy occurred in $5.2 \%$; due to secondary inefficacy, in $14.5 \%$; and by adverse events, in $4.5 \%$ of patients. ${ }^{35}$

More recently, a review of the main results of phase II and III clinical trials of secukinumab versus placebo/etanercept/ustekinumab over the past 5 years was published, including more than 3,990 patients. ${ }^{39,40}$ Anti-IL-17A was shown to be superior in reducing psoriasis symptoms and increasing quality of life. At week 4, $50 \%$ reached PASI75 and at week 16, 80\% reached PASI90 and 50\%, PASI100. In general, it was well tolerated, comparable with etanercept and ustekinumab, and associated with low immunogenicity; however, there is still a lack of results of long-term studies and experience in daily clinical practice that prove these findings.

Loss of response and partial response to biological treatment have led to the use of off-label therapeutic intensification regimens,

TABLE 1: Efficacy at the time of the main objective of the clinical trials (risk difference versus placebo)

\begin{tabular}{llcc} 
Drug & PASI50 (\%) [IC95\%] & PASI75 (\%) [IC95\%] & PASI90 (\%) [IC95\%] \\
\hline Adalimumab (s16) & $66.4(62.4-70.5)$ & $63.0(59.3-66.7)$ & $36.5(25.7-47.4)$ \\
Etanercept 25mg 2x/s or 50mg/s (s12) & $52.2(47.1-57.3)$ & $31.0(26.6-35.4)$ & $10.7(7.8-13.6)$ \\
Etanercept 50mg 2x/s (s12) & $62.0(57.8-66.1)$ & $43.5(40.0-47.1)$ & $19.3(16.6-22-0)$ \\
Infliximab (s10) & $80.5(74.4-86.5)$ & $75.7(72.1-79.3)$ & $49.5(45.6-53.4)$ \\
Ustekinumab 45mg (s12) & $76.4(72.5-80.2)$ & $70.1(65.8-74.3)$ & $47.2(42.6-51.8)$ \\
Ustekinumab 90mg (s12) & $76.8(71.7-81.9)$ & $66.5(60.2-72.9)$ & $35.5(29.0-42.0)$
\end{tabular}

Adapted from: Bonafede et al., 2013. ${ }^{33}$ 
either by increasing the dose or by shortening the administration intervals. ${ }^{41,42}$ Therapeutic intensification, although it allows avoiding secondary inefficacy, entails additional costs and, moreover, the safety of increased exposure to immunosuppressive agents is not clearly studied..$^{43}$ In addition, the use of multiple cycles of therapeutic intensification was associated with lower efficacy, with lower reductions of PASI in a second intensification cycle when compared with reduction of PASI obtained in the first cycle. ${ }^{28}$

Biotechnological therapies may lead to the development of drug-directed immune responses. Immunogenicity has been associated with low drug concentrations, reduced clinical efficacy, decreased retention rates, and increased risk of adverse events, such as perfusion and anaphylactic reactions. ${ }^{43-46}$

Neutralizing drug antibodies may reduce therapeutic activity in two ways: by blocking the binding site and by forming immunocomplexes. ${ }^{45,46}$ Neutralizing anti-drug antibodies associated with treatment with infliximab, adalimumab and ustekinumab were described. ${ }^{46}$ The biological effect of non-neutralizing anti-drug antibodies is not as clear, but may consist of increased clearance of the drug by the reticuloendothelial system. ${ }^{45}$ Table 2 summarizes the evidence to date of immunogenicity in the treatment of psoriasis.

In the future, combining the determination of serum drug concentrations and the detection of anti-drug antibodies may facilitate therapeutic optimization. ${ }^{42,45-46}$ Carrascosa et al. describe a model of therapeutic decision based on these assays, considering that, in the case of secondary inefficacy and optimal serum drug concentrations, the treatment should be replaced by a drug with a different mechanism of action. ${ }^{45-46}$ In cases of suboptimal serum concentrations, anti-drug antibodies should be dosed, with two scenarios depending on the presence or absence of anti-drug antibodies. If antibodies are positive, the drug should be replaced with another, but the mechanism of action may be maintained. In the case of negative antibodies, the dose of the drug may be increased in an attempt to improve the clinical response. ${ }^{45-46}$ However, the value of immunological tests for detecting anti-drug antibodies in daily clinical practice remains controversial. ${ }^{42}$

\section{FORMS OF PSORIASIS IN DIFFICULT-TO-TREAT LOCATIONS}

Designation of psoriasis in difficult-to-treat locations has been used by several authors for cases of psoriasis on the scalp, pal- moplantar and nail, deserving special consideration because it may be associated with an increased emotional and functional impact. Some authors also include in this designation the forms of psoriasis in sensitive areas, such as psoriasis of the face and inverse psoriasis. In addition to their location, these forms of psoriasis are characterized by the greater ineffectiveness of topical treatment and may be classified as moderate to severe psoriasis, even if BSA $\leq 10$ and PASI $\leq 10 .^{3}$ There are few controlled clinical trials evaluating the efficacy and safety of systemic therapy (conventional or biological) in these locations. In general, the existing evidence comes from clinical trials in which patients are subanalysed with this type of involvement. ${ }^{47}$

Palmoplantar psoriasis has a major impact on patients' quality of life. Often, presence of hyperkeratosis, fissures and pustules causes pain and walking difficulty. It is one of the locations where therapy is most unsatisfactory and the course of disease is more refractory. Although there is already clear scientific evidence for the use of infliximab, etanercept, adalimumab and ustekinumab in nail psoriasis, its use in palmoplantar psoriasis is less studied. ${ }^{47}$

\section{PROFILE OF PATIENTS WITH DIFFICULT-TO-TREAT PSORIASIS}

\section{Psoriasis in the elderly}

The chronic course of psoriasis and the increase in life expectancy mean that elderly patients represent a significant subset of patients with psoriasis.

Treatment of moderate to severe psoriasis in the geriatric population is challenging due to associated comorbidities, potential drug interactions and possible dose adjustment needs. In addition, few studies have evaluated the treatment of psoriasis in the elderly population, which is why, due to the concern and lack of knowledge on their safety, systemic therapies are often overlooked in favor of topical ones, sometimes resulting in an inadequate or insufficient treatment of the disease. ${ }^{48}$

Recently, in a retrospective Spanish study of systemic therapies in psoriasis, adverse events of any type were less frequent with biotechnological agents than with conventional systemic therapy, with no age dependent differences. However, severe adverse events were more common in the elderly, probably due to the characteristics of this population and not to the treatment of psoriasis itself. Risk of adverse events with biotechnological therapy was the same for both groups, young adults and elderly. Since biotechnology

\section{TABLE 2: Summary of evidence of immunogenicity in the treatment of psoriasis}

\begin{tabular}{llcccc} 
Drug & N of studies & N of patients & Anti-drug antibodies (\%) & \multicolumn{2}{c}{ Association of anti-drug antibodies with: } \\
\hline & & & & Clinical response & Adverse events \\
\cline { 2 - 5 } & 4 & 1194 & $6.0-46.0$ & Yes & No \\
Adalimumab & 1 & 160 & $5.0-9.8$ & - & No \\
Brodalumab & 1 & 188 & $4.0-25.0$ & No & No \\
\hline Etanercept & 4 & 2138 & $1.1-18.3$ & - & - \\
Golimumab & 1 & 405 & 5.4 & Yes & Yes \\
Infliximab & 5 & 675 & $19.5-51.5$ & - & - \\
Secukinumab & 2 & 413 & 0 & Yes & Yes
\end{tabular}

Source: Adapted from Balato et al., 2014.48 
appears to be safer than conventional therapy, there is a need for further studies to clarify its role in the geriatric population and to demystify its lack of safety. ${ }^{49}$

\section{Psoriasis in pregnant women}

Treatment of psoriasis in pregnant women and during breast-feeding should be approached with caution. Although the disease typically improves during pregnancy and gets worse 4 to 6 weeks postpartum, the worsening of psoriasis in $23 \%$ of women during pregnancy has also been reported. Methotrexate and acitretin are contraindicated in pregnancy and are not recommended during breast-feeding. Cyclosporine may be considered as an alternative for use in pregnant women and should be avoided during breast-feeding due to the risk of immunosuppression of the baby. Regarding biotechnology drugs, recommendations are for discontinuation for varying times prior to conception, depending on the elimination half-life, due to the absence of controlled studies in pregnant women. However, information has been accumulating regarding its use, mainly in patients with inflammatory arthritis or inflammatory bowel disease. There are concerns on immunosuppression of fetuses exposed to biotechnology drugs at the end of the second and third trimesters of pregnancy, especially for monoclonal IgG antibodies. In addition, administration of live vaccines to newborns exposed to biotechnology drugs during the end of the second and third trimesters should be postponed until 6 to 7 months after birth. Breast-feeding is not recommended during therapy with biotechnology drugs, but may be considered reasonable in the future, as the amounts of drug found in milk are negligible. Decision of biotechnology therapy during pregnancy should be made on a caseby-case basis and shared with the patient. ${ }^{50}$

\section{Psoriasis in children}

Data on psoriasis treatment in children are limited, with very few clinical trials and lack of evidence-based treatment guidelines. Therapeutic decisions are essentially based on the individu$\mathrm{al}^{\prime}$ 's experience of the clinician, having as main concern the safety of the child. Regarding adolescents, the possibility of active sexual life should be considered and, as such, categories of risk in pregnancy should be considered. ${ }^{51}$

Despite the approval restrictions and the absence of guidelines for systemic psoriasis therapy in pediatric age, particularly in relation to doses and monitoring, this is frequently used. In a recent multi-center UK audit on the treatment of moderate to severe pediatric psoriasis, refractory to topical therapy and/or phototherapy, methotrexate appears as the most prescribed agent, followed by acitretin and finally cyclosporine. Combining the data from this study with the literature review, the tolerance and safety of these drugs seem reasonable; thus, more comparative studies are needed to guide the clinician in decision making, considering their efficacy and safety. ${ }^{52}$

Psoriasis in patients with lupus erythematosus

Although the simultaneous diagnosis of psoriasis and lupus erythematosus is rare, coexistence of these diagnoses requires a careful therapeutic selection. On the one hand, phototherapy is contraindicated and, on the other hand, the potential for induction of systemic lupus erythematosus by anti-TNF should be considered. ${ }^{53}$ Preferred therapies in this situation, according to the consensus of a panel of experts and in order of preference are methotrexate, acitre- tin, combination of methotrexate with anti-TNF, ustekinumab and cyclosporine. ${ }^{54-55}$

\section{Psoriasis in the obese patient}

Obesity, especially abdominal obesity, is considered a lowgrade pro-inflammatory state, which increases the risk of cardiovascular disease and metabolic syndrome. Recently, several studies have been documenting a clear association between obesity and psoriasis. Relation between body mass index (BMI) and severity and extent of psoriasis lesions (PASI) appears to be direct and bidirectional. ${ }^{56-57}$

In addition, obesity has important implications for psoriasis therapy. This is in line with the increased risk of adverse events to conventional drugs, such as hepatotoxicity to methotrexate, which is more prevalent in patients with hepatic steatosis, and reduced efficacy and/or increased costs of biotechnology therapy, whose dose should be adjusted to patient's weight. ${ }^{33,58}$ Apart from infliximab, dosage regimens of biotechnological agents approved in Europe do not consider the patient's weight, except for ustekinumab, whose dose is doubled in patients weighing more than $100 \mathrm{~kg}$, which may partially explain variation in efficacy of this agent found among patients with different BMI.

Bariatric surgery, particularly gastric bypass, has been shown to be a promising tool in obese patients with refractory psoriasis, not only by weight loss per se but also by postprandial increase in GLP-1 levels. However, more studies are needed in this field. ${ }^{59}$

\section{THE PATIENT PERSPECTIVE}

\section{Satisfaction with treatment}

Although self-completion questionnaires are considered to be well-accepted methods of determining patient satisfaction, there is a great diversity of questionnaires used, not all validated, and there is no definition of the concept of satisfaction or dissatisfaction, which makes it difficult to interpret studies on the theme. ${ }^{60}$

In psoriasis, patient satisfaction has been associated with the type of treatment. ${ }^{5,61-64}$ In patients receiving topical therapy, phototherapy, or systemic therapies, only $24-27 \%$ reported to be "very satisfied" [satisfaction level $\geq 8$ (0-10)], with higher satisfaction levels in patients treated with systemic therapies (26-63\%).,61 Similarly, with an equivalent definition, Nijsten et al. found that only less than $40 \%$ of patients were "very satisfied" with conventional systemic treatments. ${ }^{65}$ Levels of satisfaction associated with biological treatments were significantly higher than those associated with topical therapies, phototherapy and conventional systemic therapies, although using different satisfaction questionnaires and, consequently, different definitions of satisfaction..$^{62-64,66,67}$ However, $49 \%$ of patients still don't consider themselves "highly" or "completely" satisfied, despite biological treatment, or in another study, only $45 \%$ of patients on biological treatment were "very satisfied". ${ }^{62,66}$

Van den Reek et al. evaluated, prospectively, the satisfaction with biological treatment (adalimumab, etanercept and ustekinumab) in a routine follow-up, observing significant improvements in the four domains of the questionnaire used (effectiveness, toxicity, convenience and overall satisfaction) at 3 and 6 months of treatment (all $\mathrm{p} \leq 0.02$ ). The authors demonstrated that the "effectiveness" domain is the most likely to improve, in a manner consistent with what 
had previously been described, and therefore conclude that, in order to overcome the need for satisfaction, more effective therapies will have to be available. ${ }^{68}$

\section{Adherence to therapy}

Adherence to therapy is a major challenge in the treatment of patients with psoriasis. ${ }^{69}$ The World Health Organization has recognized therapeutic adherence in chronic diseases as one of the most important factors for effective therapy. ${ }^{70}$

There is no standardized methodology to evaluate adherence to prescribed therapy, and its evaluation and interpretation is complex. ${ }^{71}$

In a study evaluating acquisition of drugs, topical and systemic, initially prescribed (primary adhesion) to patients with dermatological conditions (psoriasis, acne, eczema and infections), patients with psoriasis were the least adherent, with $44.2 \%$ not getting the prescribed treatment. ${ }^{72}$

In a systematic review on adherence to treatment of patients with psoriasis, which included studies with methodologies for quantifying adherence to various therapies, adherence was quantified between $27-92 \%$. After exclusion of some critically evaluated studies regarding deviations inherent to the methodology, the authors considered that adherence to psoriasis therapy should be approximately $50-60 \%{ }^{73}$

In psoriasis, adherence to biotechnology treatment was significantly higher than adherence to non-biological treatments. ${ }^{74,75}$ Bohsle et al. found $66 \%$ adherence to biotechnology treatment, significantly higher than adherence to other non-biotechnological treatments, of $36 \%$. In this study, adherence did not differ significantly between biotechnological treatments studied (alefacept, efalizumab, etanercept)..$^{75}$ Also, Chan et al. verified through a validated self-completion questionnaire that the type of therapy significantly influenced adherence, being markedly superior for biological, oral or phototherapy treatments in relation to topical treatments. Adherence to the biotechnological treatment, quantified at $100 \%$, was superior to all other treatment modalities. There were no differences in adherence levels in relation to the different treatments studied (adalimumab, etanercept and infliximab) and in relation to the type of presentation. Among the sociodemographic factors studied, only tobacco consumption showed an inverse relation to adherence to treatment. $^{74}$

\section{DISCUSSION}

Eleven years after the approval of the first biotechnology drug for the treatment of moderate to severe psoriasis, which revolutionized the treatment of this disease and contribute to better patient satisfaction and compliance, patients still have medical needs to be met. Patients who have exhausted all available biotechnology therapeutic alternatives with accumulation of primary, secondary and/or toxicities ineffectiveness, needing new therapeutic interventions, begin to emerge. In addition, there are forms of psoriasis in difficult-to-treat locations and types of patients with severe psoriasis requiring an individualized approach and a judicious therapeutic decision.

Although biotechnology therapy has brought gains in terms of efficacy, safety and therapeutic adherence, $85 \%$ of patients still express the need for better therapies. ${ }^{66}$

Effectiveness of therapies appears to be the main reason for discontinuation of treatment and as the most important determinant of patient satisfaction, and therefore the need for more effective therapies for the treatment of moderate to severe psoriasis urges. $\square$

\section{REFERENCES}

1. Pathirana D, Ormerod AD, Saiag P, Smith C, Spuls PI, Nast A, et al. European S3Guidelines on the systemic treatment of psoriasis vulgaris. J Eur Acad Dermatol Venereol. 2009;23:1-70.

2. Langley RG, Krueger GG, Griffiths CE. Psoriasis: epidemiology, clinical features, and quality of life. Ann Rheum Dis. 2005;64:ii18-23

3. Mrowietz U, Kragballe K, Reich K, Spuls P, Griffiths CE, Nast A, et al. Definition of treatment goals for moderate to severe psoriasis: a European consensus. Arch Dermatol Res. 2011;303:1-10

4. Dubertret L, Mrowietz U, Ranki A, van de Kerkhof PC, Chimenti S, Lotti T, et al, on behalf of the EUROPSO patient survey. European patient perspectives on the impact of psoriasis: the EUROPSO patient membership survey. $\mathrm{Br} \mathrm{J}$ Dermatol. 2006;155:729-36.

5. Reich K. The concept of psoriasis as a systemic inflammation: implications for disease management. J Eur Acad Dermatol Venereol. 2012;26:3-11.

6. Daudén E, Castañeda S, Suárez C, García-Campayo J, Blasco AJ, Aguilar MD, et al, on behalf of the Working Group on Comorbidity in Psoriasis. Clinical practice guideline for an integrated approach to comorbidity in patients with psoriasis. $J$ Eur Acad Dermatol Venereol. 2013;27:1387-404.
7. Ni C, Chiu MW. Psoriasis and comorbidities: links and risks. Clin Cosmet Investig Dermatol. 2014;7:119-32.

8. Vincent FB, Morand EF, Murphy K, Mackay F, Mariette X, Marcelli C. Antidrug antibodies (ADAb) to tumour necrosis factor (TNF)-specific neutralising agents in chronic inflammatory diseases: a real issue, a clinical perspective. Ann Rheum Dis. 2013;72:165-78.

9. Nestle F0, Kaplan DH, Barker J. Psoriasis. N Engl J Med. 2009;361:496-509.

10. Lynde CW, Poulin Y, Vender R, Bourcier M, Khalil S. Interleukin 17A: Toward a new understanding of psoriasis pathogenesis. J Am Acad Dermatol. 2014;71:141-50.

11. Chiricozzi A, Saraceno R, Chimenti MS, Guttman-Yassky E, Krueger JG. Role of IL-23 in the pathogenesis of psoriasis: a novel potential therapeutic target? Expert Opin Ther Targets. 2014;18:513-25.

12. Levin AA, Gottlieb AB. Specific targeting of interleukin-23p19 as effective treatment for psoriasis. J Am Acad Dermatol. 2014;70:555-61.

13. Girolomoni G, Mrowietz U, Paul C. Psoriasis: rationale for targeting interleukin-17. Br J Dermatol. 2012;167:717-24.

14. Brown G, Malakouti M, Wang E, Koo JY, Levin E. Anti-IL-17 phase II data for psoriasis: A review. J Dermatolog Treat. 2015;26:32-6. 
15. Helling B, König M, Dälken B, Engling A, Krömer W, Heim K, et al. A specific CD4 epitope bound by tregalizumab mediates activation of regulatory $T$ cells by a unique signaling pathway. Immunol Cell Biol. 2015;93:396-405.

16. Jiang W, Zhu FG, Bhagat L, Yu D, Tang JX, Kandimalla ER, et al. A Toll-like receptor 7, 8 , and 9 antagonist inhibits Th1 and Th17 responses and inflammasome activation in a model of IL-23-induced psoriasis. J Invest Dermatol. 2013;133:1777-84.

17. Hsu L, Armstrong AW. JAK inhibitors: treatment efficacy and safety profile in patients with psoriasis. J Immunol Res. 2014;2014:283617.

18. Papp KA, Menter A, Strober B, Langley RG, Buonanno M, Wolk R, et al. Efficacy and safety of tofacitinib, an oral Janus kinase inhibitor, in the treatment of psoriasis: a Phase $2 \mathrm{~b}$ randomized placebo-controlled dose-ranging study. $\mathrm{Br} \mathrm{J}$ Dermatol. 2012;167:668-77.

19. Ports WC, Khan S, Lan S, Lamba M, Bolduc C, Bissonnette R, et al. A randomized phase 2a efficacy and safety trial of the topical Janus kinase inhibitor tofacitinib in the treatment of chronic plaque psoriasis. Br J Dermatol. 2013;169:137-45.

20. Gottlieb AB, Matheson RT, Menter A, Leonardi CL, Day RM, Hu C, et al. Efficacy, tolerability, and pharmacodynamics of apremilast in recalcitrant plaque psoriasis: a phase II open-label study. J Drugs Dermatol. 2013;12:888-97.

21. Moustafa F, Feldman SR. A review of phosphodiesterase-inhibition and the potential role for phosphodiesterase 4-inhibitors in clinical dermatology. Dermatol Online J. 2014;20:22608.

22. Dgs.pt [Internet]. Norma $n^{0} 065 / 2011$ de 30/12/2011 atualizada a 28/10/2014: Tratamento da Psoríase com Agentes Biológicos no Doente Adulto. [acesso dia mês ano]. Disponível em http://www.dgs.pt/normas-clinicas/normas-clinicas.aspx.

23. McClure SL, Valentine J, Gordon KB. Comparative tolerability of systemic treatments for plaque-type psoriasis. Drug Saf. 2002;25:913-27.

24. Christophers E, Griffiths CE, Gaitanis G, van de Kerkhof P. The unmet treatment need for moderate to severe psoriasis: results of a survey and chart review. J Eur Acad Dermatol Venereol. 2006;20:921-5.

25. Ferrándiz C, Carrascosa JM, Boada A. A new era in the management of psoriasis? The biologics: facts and controversies. Clin Dermatol. 2010:28:81-7.

26. Svedbom A, Dalén J, Mamolo C, Cappelleri JC, Petersson IF, Ståhle M. Treatment patterns with topicals, traditional systemics and biologics in psoriasis - a Swedish database analysis. J Eur Acad Dermatol Venereol. 2015;29:215-23.

27. Van Vollenhoven RF. Switching between anti-tumour necrosis factors: trying to get a handle on a complex issue. Ann Rheum Dis. 2007;66:849-51.

28. van den Reek JM, van Lümig PP, Kievit W, Zweegers J, van de Kerkhof PC, Seyger $\mathrm{MM}$, et al. Effectiveness of adalimumab dose escalation, combination therapy of adalimumab with methotrexate, or both in patients with psoriasis in daily practice. J Dermatolog Treat. 2013:24:361-8.

29. de Groot M, Appelman M, Spuls PI, de Rie MA, Bos JD. Initial experience with routine administration of etanercept in psoriasis. Br J Dermatol. 2006;155:808-14.

30. Puig L, López A, Vilarrasa E, García I. Efficacy of biologics in the treatment of moderate-to-severe plaque psoriasis: a systematic review and meta-analysis of randomized controlled trials with different time points. J Eur Acad Dermatol Venereol. 2014;28:1633-53.

31. Levin EC, Gupta R, Brown G, Malakouti M, Koo J. Biologic fatigue in psoriasis. J Dermatolog Treat. 2014;25:78-82.

32. Khalid JM, Globe G, Fox KM, Chau D, Maguire A, Chiou CF. Treatment and referral patterns for psoriasis in United Kingdom primary care: a retrospective cohort study. BMC Dermatol. 2013;13:9.

33. Bonafede M, Johnson BH, Fox KM, Watson C, Gandra SR. Treatment patterns with etanercept and adalimumab for psoriatic diseases in a real-world setting. J Dermatolog Treat. 2013;24:369-73.

34. van den Reek JM, Zweegers J, Kievit W, Otero ME, van Lümig PP, Driessen RJ, et al. 'Happy' drug survival of adalimumab, etanercept and ustekinumab in psoriasis in daily practice care - results from the BioCAPTURE network. Br J Dermatol. 2014; 171:1189-96.

35. Esposito M, Gisondi P, Cassano N, Ferrucci G, Del Giglio M, Loconsole F, et al. Survival rate of antitumour necrosis factor- $\square$ treatments for psoriasis in routine dermatological practice: a multicentre observational study. $\mathrm{Br} \mathrm{J}$ Dermatol. 2013;169:666-72.

36. Gniadecki R, Kragballe K, Dam TN, Skov L Comparison of drug survival rates for adalimumab, etanercept and infliximab in patients with psoriasis vulgaris. $\mathrm{Br} \mathrm{J}$ Dermatol. 2011;164:1091-6.

37. Gniadecki R, Bang B, Bryld LE, Iversen L, Lasthein S, Skov L. Comparison of longterm drug survival and safety of biologic agents in patients with psoriasis vulgaris. Br J Dermatol. 2015;172:244-52

38. Carrascosa JM, Vilavella M, Garcia-Doval I, Carretero G, Vanaclocha F, Daudén $E$, et al. Body mass index in patients with moderate-to-severe psoriasis in Spain and its impact as an independent risk factor for therapy withdrawal: results of the Biobadaderm Registry. J Eur Acad Dermatol Venereol. 2014;28:907-14.

39. Langley RG, Elewski BE, Lebwohl M, Reich K, Griffiths CE, Papp K, et al; ERASURE Study Group; FIXTURE Study Group. Secukinumab in plaque psoriasis--results of two phase 3 trials. N Engl J Med. 2014;371:326-38.

40. López-Ferrer A, Vilarrasa E, Puig L. Secukinumab (AIN457) for the treatment of psoriasis. Expert Rev Clin Immunol. 2015;11:1177-88.

41. Brezinski EA, Armstrong AW. Off-Label Biologic Regimens in Psoriasis: A Systematic Review of Efficacy and Safety of Dose Escalation, Reduction, and Interrupted Biologic Therapy. PLoS One. 2012;7:e33486.

42. Mrowietz U, Steinz K, Gerdes S. Psoriasis: to treat or to manage? Exp Dermatol. 2014;23:705-9.

43. Puig L. Tratamiento de la psoriasis en placas moderada a grave con fármacos biológicos: análisis del sobrecoste de la intensificación temporal frente a cambio a otro biológico en caso de fracaso secundario. Actas Dermosifiliogr. 2014;105:401-12

44. De Simone C, Amerio P, Amoruso G, Bardazzi F, Campanati A, Conti A, et al. Immunogenicity of anti-TNFa therapy in psoriasis: a clinical issue? Expert Opin Biol Ther. 2013;13:1673-82.

45. Carrascosa JM. Inmunogenicidad en terapia biológica. Implicaciones en Dermatología. Actas Dermosifiliogr. 2013;104:471-9.

46. Carrascosa JM, van Doorn MB, Lahfa M, Nestle F0, Jullien D, Prinz JC. Clinica relevance of immunogenicity of biologics in psoriasis: implications for treatment strategies. J Eur Acad Dermatol Venereol. 2014;28:1424-30.

47. Sánchez-Regaña M, Aldunce Soto MJ, Belinchón Romero I, Ribera Pibernat M, Lafuente-Urrez RF, Carrascosa Carrillo JM, et al. En representación del Grupo Español de Psoriasis de la Academia Española de Dermatología y Venereología. Directrices del grupo español de psoriasis (GEP) basadas en la evidencia para el uso de medicamentos biológicos en pacientes con psoriasis en localizaciones de difícil tratamiento (uñas, cuero cabelludo, palmas y plantas). Actas Dermosifiliogr. 2014;105:923-34

48. Balato N, Patruno C, Napolitano M, Patrì A, Ayala F, Scarpa R. Managing moderateto-severe psoriasis in the elderly. Drugs Aging. 2014;31:233-8.

49. Medina C, Carretero G, Ferrandiz C, Dauden E, Vanaclocha F, Gómez-García FJ, et al. Safety of classic and biologic systemic therapies for the treatment of psoriasis in elderly: an observational study from national BIOBADADERM registry. . J Eur Acad Dermatol Venereol. 2015;29:858-64.

50. Mervic L. Management of moderate to severe plaque psoriasis in pregnancy and lactation in the era of biologics. Acta Dermatovenerol Alp Pannonica Adriat. 2014;23:27-31.

51. Cather JC. Psoriasis in children and women: addressing some special needs Semin Cutan Med Surg. 2014;33:S42-4.

52. Burden-Teh E, Lam ML, Taibjee SM, Taylor A, Webster S, Dolman S, et al. How are we using systemic drugs to treat psoriasis in children? An insight into current clinical U.K. practice. Br J Dermatol. 2015 Aug;173:614-8

53. Pirowska MM, Goździalska A, Lipko-Godlewska S, Obtułowicz A, Sułowicz J, Podolec $\mathrm{K}$, et al. Autoimmunogenicity during anti-TNF therapy in patients with psoriasis and psoriatic arthritis. Postepy Dermatol Alergol. 2015;32:250-4.

54. Strober BE, Clay Cather J, Cohen D, Crowley JJ, Gordon KB, Gottlieb AB, et al. A Delphi Consensus Approach to Challenging Case Scenarios in Moderate-toSevere Psoriasis: Part 1. Dermatol Ther (Heidelb). 2012;2:1.

55. Varada S, Gottlieb AB, Merola JF, Saraiya AR, Tintle SJ. Treatment of coexistent psoriasis and lupus erythematosus. J Am Acad Dermatol. 2015;72:253-60.

56. Carrascosa JM, Rocamora V, Fernandez-Torres RM, Jimenez-Puya R, Moreno JC, Coll-Puigserver $\mathrm{N}$, et al. Obesity and psoriasis: inflammatory nature of obesity, relationship between psoriasis and obesity, and therapeutic implications. Actas Dermosifiliogr. 2014;105:31-44.

57. Duarte GV, Oliveira Mde F, Cardoso TM, Follador I, Silva TS, Cavalheiro CM, et al. Association between obesity measured by diferente parameters and severity of psoriasis. Int J Dermatol. 2013;52:177-81.

58. Puig L. Obesity and psoriasis: body weight and body mass index influence the response to biological treatment. J Eur Acad Dermatol Venereol. 2011;25:1007-11.

59. Sako EY, Famenini S, Wu JJ. Bariatric surgery and psoriasis. J Am Acad Dermatol. 2014;70:774-9.

60. Barbosa CD, Balp MM, Kulich K, Germain N, Rofail D.. A literature review to explore the link between treatment satisfaction and adherence, compliance, and persistence. Patient Prefer Adherence. 2012;6:39-48.

61. Poulin Y, Papp KA, Wasel NR, Andrew R, Fraquelli E, Bernstein G, et al. A Canadian online survey to evaluate awareness and treatment satisfaction in individuals with moderate to severe plaque psoriasis. Int J Dermatol. 2010;49:1368-75.

62. Christophers E, Segaert S, Milligan G, Molta CT, Boggs R. Clinical improvement and satisfaction with biologic therapy in patients with severe plaque psoriasis: results of a European cross-sectional observational study. J Dermatolog Treat. 2013;24:193-8.

63. van Cranenburgh OD, de Korte J, Sprangers MA, de Rie MA, Smets EM. Satisfaction with treatment among patients with psoriasis: a web-based survey study. Br J Dermatol. 2013;169:398-405. 
64. Ragnarson Tennvall G, Hjortsberg C, Bjarnason A, Gniadecki R, Heikkilä H, Jemec $\mathrm{GB}$, et al. Treatment patterns, treatment satisfaction, severity of disease problems, and quality of life in patients with psoriasis in three Nordic countries. Acta Derm Venereol. 2013;93:442-5.

65. Nijsten T, Margolis DJ, Feldman SR, Rolstad T, Stern RS. Traditional systemic treatments have not fully met the needs of psoriasis patients: results from a national survey. J Am Acad Dermatol. 2005;52:434-44

66. Lebwohl MG, Bachelez H, Barker J, Girolomoni G, Kavanaugh A, Langley RG, et al. Patient perspectives in the management of psoriasis: results from the populationbased Multinational Assessment of Psoriasis and Psoriatic Arthritis Survey. J Am Acad Dermatol. 2014;70:871-81.e1-30

67. Hjortsberg C, Bergman A, Bjarnason A, Heikkilä H, Hjelmgren J, Svensson A, et al. Are treatment satisfaction, quality of life, and self-assessed disease severity relevant parameters for patient registries? Experiences from Finnish and Swedish patients with psoriasis. Acta Derm Venereol. 2011;91:409-14.

68. van den Reek JM, van Lüumig PP, Otero ME, Zweegers J, van de Kerkhof PC, Ossenkoppele PM, et al. Satisfaction of treatment with biologics is high in psoriasis: results from the Bio-CAPTURE network. Br J Dermatol. 2014;170:1158-65.

69. Bewley A, Page B. Maximizing patient adherence for optimal outcomes in psoriasis. J Eur Acad Dermatol Venereol. 2011;25:9-14.

70. World Health Organization. Adherence to Long-Term Therapies: Evidence for Action. Geneva: World Health Organization; 2003.

71. Li Y, Zhou H, Cai B, Kahler KH, Tian H, Gabriel S, Arcona S. Group-based trajectory modeling to assess adherence to biologics among patients with psoriasis. Clinicoecon Outcomes Res. 2014 Apr 10;6:197-208.

72. Storm A, Andersen SE, Benfeldt E, Serup J. One in 3 prescriptions are never redeemed: primary nonadherence in an outpatient clinic. J Am Acad Dermatol. 2008;59:27-33

73. Augustin M, Holland B, Dartsch D, Langenbruch A, Radtke MA. Adherence in the treatment of psoriasis: a systematic review. Dermatology. 2011;222:363-74.

74. Chan SA, Hussain F, Lawson LG, Ormerod AD. Factors affecting adherence to treatment of psoriasis: comparing biologic therapy to other modalities. J Dermatolog Treat. 2013;24:64-9.

75. Bhosle MJ, Feldman SR, Camacho FT, Timothy Whitmire J, Nahata MC, Balkrishnan R. Medication adherence and health care costs associated with biologics in Medicaid-enrolled patients with psoriasis. J Dermatolog Treat. 2006;17:294-301.
MAILING ADDRESS:

Sofia Magina

Alameda Professor Hernani Monteiro

4200-319 Porto

Email: sofiavasconcelosmagina@gmail.com

How to cite this article: Vide J, Magina S. Moderate to severe psoriasis treatment challenges through the era of biological drugs . An Bras Dermatol. 2017;92(5):668-74. 